\title{
Exploring the impacts of COVID-19 related social distancing on loneliness, psychological needs and symptomatology
}

\author{
Bruno Faustino, ${ }^{1,2}$ António Branco Vasco,,${ }^{1,2}$ João Delgado, ${ }^{1}$ António Farinha-Fernandes, ${ }^{1}$ José Carlos Guerreiro ${ }^{1}$ \\ ${ }^{1}$ Faculty of Psychology of the University of Lisbon; ${ }^{2}$ Department of Cognitive, Behavioral and Integrative Psychotherapy, Faculty of \\ Psychology, University of Lisbon, Lisbon, Portugal
}

\begin{abstract}
Loneliness may be a consequence of social distancing, a measure imposed by several governments to try to reduce the contagion of severe acute respiratory syndrome-related coronavirus 2 (SARS-CoV-2). Despite being necessary, this measure may have thus caused a rise in mental health issues, leading to higher psychological distress and symptomatology. Thus, it is also important to explore how loneliness relates to the regulation of psychological needs. This study aims to explore the relationships between loneliness, symptomatology, and the regulation of psychological needs. 142 individuals $(\mathrm{M}$ age=32.7, $\mathrm{SD}=10.9$ ), answered self-report questionnaires in a cross-sectional design. Results show that loneliness is positively correlated with symptomatology and difficulties in the regulation of psychological needs, with these relationships being mediated by psychological distress and psychological well-being. We discuss our results with a focus on loneliness and related psychopathological symptomatology, as they seem to be core factors in the regulation of psychological needs.
\end{abstract}

Key words: Loneliness; mental health; symptoms; psychological well-being; psychological distress; psychological needs; COVID-19.

\section{Introduction}

Across different countries, several measures were adopted to contain the coronavirus disease 2019 (COVID19) pandemic (World Health Organization, 2020a,b). One fundamental measure was self-imposed quarantine or selfisolation. Although this measure is essential to reduce the number of severe acute respiratory syndrome-related coronavirus 2 (SARS-CoV-2) infections, it can facilitate the onset of psychopathological symptoms, such as stress, anxiety or depressive symptoms (Wang et al., 2017). In some countries, including Portugal, a great number of in-

Correspondence: Bruno Faustino, Faculdade de Psicologia da Universidade de Lisboa, Portugal.

E-mail: brunofaustino.research@gmail.com

Citation: Faustino, B., Vasco, A. B., Delgado, J., Farinha-Fernandes A., \& Guerreiro, J. C. (2020). Exploring the impacts of COVID-19 related social distancing on loneliness, psychological needs and symptomatology. Research in Psychotherapy: Psychopathology, Process and Outcome, 23(3), 222-230. doi: 10.4081/ripppo. 2020.492

Received for publication: 4 September 2020

Revision received: 29 November 2020.

Accepted for publication: 29 November 2020.

This work is licensed under a Creative Commons Attribution NonCommercial 4.0 License (CC BY-NC 4.0).

${ }^{\circ}$ Copyright: the Author(s), 2020

Licensee PAGEPress, Italy

Research in Psychotherapy:

Psychopathology, Process and Outcome 2020; 23:222-230

doi:10.4081/ripppo.2020.492 dividuals were away from their workspaces and social gatherings for more than two months. Importantly, social isolation is empirically associated with loneliness (Cornwell \& Waite, 2009), which may be viewed as the psychological counterpart of social isolation (Shankar, McMunn, Banks, \& Steptoe, 2011).

Elevations of psychopathological symptoms associated with pandemics are well documented in the literature (Kamara et al., 2012; Liu et al., 2012; Moukaddam, 2019; Ziegler, Mamahit \& Cox, 2018). In the first severe acute respiratory syndrome (SARS) epidemic in 2003, different studies reported increased indexes of depression and anxiety (Chan et al., 2007; Liu et al., 2012), and post-traumatic stress disorder symptomatology (Hawryluck et al., 2004; Liu et al., 2012). Regarding the actual SARS coronavirus 2 (SARS-CoV-2) pandemic, Qiu and collaborators (2020), documented an increase in psychological distress (e.g., depression, anxiety, and suicide attempts), while Liu and collaborators (2020) reported an increase in traumatic stress disorder symptomatology in China. In Italy, higher levels of psychological distress were associated with the number of days in lockdown (Conversano et al., 2020; Marazziti et al., 2020) Recently, Salari and collaborators (2020) documented higher rates of COVID-19 related depression $(33.7 \%)$, stress $(29.6 \%)$, and anxiety $(31.9 \%)$. Prout and collaborators (2020), using a machine learning algorithm, found that somatization and less reliance on adaptive defenses were associated with COVID-19 related distress. Finally, Brooks and collaborators (2020) emphasized that periods of isolation (even less than 10 days), may have effects on the emerge of psychopathological symptoms. Thus, several authors expressed concerns due to the COVID-19 lockdowns and/or quarantine regarding anxiety, depression, 
panic, loneliness, stress, difficulties in concentrating, or desperation (Banerjee, 2020; Brooks et al., 2020; Dickerson, 2020; Hiremath et al., 2020; Wang et al., 2017; Zandifar \& Badrfam, 2020). Taken all together, it is expected that feelings of isolation, deprivation, and loneliness may arise in some people due to the social distancing measures, with a potential impact on mental health.

Loneliness is a pervasive problem in modern societies and may be described as one's awareness about deficits in social and interpersonal relationships with enduring emotional reactions such as sadness, internal emptiness, and/or longing (Ascher \& Paquette, 2003; Weiss, 1973). Traditionally, loneliness was conceptualized as a gnawing sensation or chronic distress (Weiss, 1973), but recently it has been described using biological constructs, such as an emotional state that signals the need of behavior change to avoid psychological damage (Masi, Chen, Hawkley, \& Cacioppo, 2011). Initially, Weiss (1973) differentiated emotional and social loneliness. Emotional loneliness was seen as a consequence of the privation/absence of an emotionally close relationship - emotional connections (e.g., partner, confident). Social loneliness, in contrast, emerged due to the lack of group ties and the lack of shared enjoyable and pleasurable activities (Weiss, 1973). Previous research showed that the experience of loneliness may be decomposed in several dimensions/factors, but since they are highly correlated loneliness tends to be viewed as a unidimensional construct (Hawkley, Browne, \& Cacioppo, 2005; Masi et al., 2011; Russell, 1996; Russel et al., 1984). Loneliness is not only associated with feelings of isolation, not belonging and disconnectedness (Hawkley, Browne, \& Cacioppo, 2005), psychological distress and symptomatology (Cornwell \& Waite, 2009; Gerino et al., 2017; Masi et al., 2011; Sousa et al., 2017), but also with physical illness, such as cardiovascular disease, high blood pressure, high total cholesterol, and overweightness (Caspi et al., 2006; Masi et al., 2011). Moreover, loneliness is a significant predictor of mortality (Holt-Lunstad, Smith, Baker, Harris, \& Stephenson, 2015). Thus, loneliness may be an emerging public health problem (Cacioppo \& Cacioppo, 2018). However, data is still lacking to understand how individuals are experiencing COVID-19 related loneliness in Portugal. Furthermore, advanced models such as mediations were not yet used to explore how loneliness relates to symptomatology and mental health in the context of the COVID-19 pandemic.

Recent findings in the integrative psychotherapy research paradigms show that the regulation of psychological needs may lie at the core of mental health (Barreira, 2016; Castelo-Branco, 2016; Faustino \& Vasco, 2020b,c; Faustino, Vasco, Silva, \& Marques, 2020; Fonseca, 2012; Martins, 2016; Sol \& Vasco, 2017). Psychological needs are states of organismic imbalance caused by a significant lack of psychological nutrients, which is signaled by the emotional system (Vasco, Conceição, Silva, Ferreira, \& Vaz-Velho, 2018). As self-quarantine implies social distancing, it is therefore expected that individuals start to experi- ence feelings of loneliness, leading to psychological distress and the lack of well-being, which causes an impact on the regulation of psychological needs. Emotional pain, suffering, and vulnerable states may be viewed as disturbances of the emotional system, which signals the degree of the regulation of psychological needs (Sol \& Vasco, 2017; Vasco et al., 2018). Thus, psychological distress and the lack of well-being are significant predictors of the regulation of psychological needs and psychopathological symptoms (Faustino \& Vasco, 2020a). However, some assumptions regarding loneliness and the regulation of psychological needs were not yet empirically explored. Regarding the association between psychological needs and mental health, it is expected that the social distancing measures related to the COVID-19 pandemic may have some impacts on this relationship.

It is expected that the quarantine/social distance measures may facilitate feelings of loneliness with impacts on psychological distress and the lack of well-being, which facilitates difficulties in the regulation of psychological needs. Thus, it is expected that individuals who experience loneliness may also foster psychopathological symptoms (Banerjee, 2020; Brooks et al., 2020; Prout et al., 2020).

\section{Aims and hypothesis}

This study aims to explore associations and the mediational role of psychological distress and well-being on the relationship between loneliness and the regulation of psychological needs, as well as on the relationship between loneliness and symptomatology. Therefore, based on the literature review, our hypotheses are as follows: H1: Psychological needs, symptomatology, loneliness, well-being, and distress are correlated;

H2: The relationship between loneliness and symptomatology is mediated by psychological distress and wellbeing;

H3: The relationship between loneliness and the regulation of psychological needs is mediated by psychological distress and well-being.

\section{Methods}

\section{Participants and procedures}

Participants from the general population were recruited online through social media (e.g., Facebook, LinkedIn), by responding to an announcement of the study. By clicking on the link in the announcement, they were redirected to the explanation of the study. All individuals were tested individually in the period between the $20^{\text {th }}$ of April and the $20^{\text {th }}$ of May of 2020, within 6 days to finalize the research protocol. During that period, Portugal was under severe quarantine measures. Inclusion criteria were to be in selfquarantine, to be older than 18 years and younger than 90 , to be in self-quarantine for more than 15 days, and not hav- 
ing a major neurocognitive disorder. Informed consent was given to all individuals and there was not any compensation for participating in the study. The present research was approved by the ethics committee of the Faculty of Psychology of University of Lisbon.

Quarantine measures started equally in Portugal on the 22 of March and were raised in middle June. These measures legislated obligatory confinement to: i) individuals who were infected or ill with COVID-19; and ii) individuals from risk groups (e.g., chronic diseases, older adults). Telework became mandatory if possible and all citizens had restrictions on public circulation, with few exceptions (e.g., policies, health workers, firemen). All cultural, religious, sports, and academic activities were forbidden, and all shopping malls and commerce were obligated to close at eight o'clock.

The sample consisted of 142 participants, 40 males $(28.2 \%)$, and 102 females $(71.8 \%)$. The age of men varied between 18 and 72 years $(\mathrm{M}=35.7, \mathrm{SD}=13.8)$, and the age of women ranged from 18 to 71 years $(M=31.5$, $\mathrm{SD}=10.9)$. Education frequencies were $1(0.7 \%)$ with 9 years of education, $28(19.7 \%)$ with 12 years, $54(38.0 \%)$ with a bachelor's degree, $55(38.7 \%)$ with a master's degree, and $5(2.87 \%)$ with a doctoral degree (see Table 1$)$.

\section{Measures}

\section{Needs Satisfaction Regulation Scale (NSRS-43)}

In the present study, the regulation of psychological needs was evaluated using the NSRS-43 (Conde et al., 2012). This self-report scale with 43 items aims to assess the degree to which individuals can regulate their own psychological needs. It measures fourteen subscales that represent fourteen psychological needs (e.g., proximity, control, or self-esteem), and has a general index factor. The response format is an 8-point Likert scale. Cronbach's alfa of the general index was considered adequate $(\alpha=0.83)$.

\section{Mental Health Inventory (MHI)}

The Portuguese version of the MHI (Ribeiro, 2001) was used to assess psychological well-being and psychological distress. The MHI is a self-report questionnaire with 38 items rated on a Likert scale of five or six values that aims to assess several domains of mental health. Cronbach's alpha for psychological well-being $(\alpha=0.88)$ and for psychological distress $(\alpha=0.91)$ were considered very good.

Table 1. Descriptive statistics.

\begin{tabular}{|c|c|c|c|c|c|c|}
\hline & $\mathbf{n}$ & $\%$ & M & SD & Amp & Min-Max \\
\hline Day in self-imposed quarantine & 142 & 100 & 47.3 & 12.0 & 85 & $5-90$ \\
\hline Age & 142 & 100 & 32.7 & 10.9 & 54 & $18-72$ \\
\hline \multicolumn{7}{|l|}{ Gender } \\
\hline Men & 40 & 28.2 & & & & \\
\hline Women & 102 & 71.8 & & & & \\
\hline \multicolumn{7}{|l|}{ Educational level } \\
\hline$<9$ years & 1 & 0.7 & & & & \\
\hline Secondary & 28 & 19.7 & & & & \\
\hline Bachelor's degree & 54 & 38.0 & & & & \\
\hline Master's degree & 55 & 38.7 & & & & \\
\hline Doctoral degree & 4 & 2.87 & & & & \\
\hline \multicolumn{7}{|l|}{ Occupation } \\
\hline Working & 7 & 4.9 & & & & \\
\hline Telework & 53 & 37.3 & & & & \\
\hline Lay-off & 13 & 9.2 & & & & \\
\hline Unemployed & 25 & 17.6 & & & & \\
\hline Student & 37 & 26.1 & & & & \\
\hline Student/worker & 4 & 2.8 & & & & \\
\hline Retired & 3 & 2.1 & & & & \\
\hline \multicolumn{7}{|l|}{ Marital Status } \\
\hline Single & 94 & 66.2 & & & & \\
\hline Married & 21 & 14.8 & & & & \\
\hline Fact Union & 17 & 12.0 & & & & \\
\hline Divorced & 10 & 7.0 & & & & \\
\hline \multicolumn{7}{|l|}{ Psychological treatment } \\
\hline Yes & 17 & 12.0 & & & & \\
\hline No & 125 & 88.8 & & & & \\
\hline \multicolumn{7}{|l|}{ Self-reported diagnosis } \\
\hline Yes & 6 & 4.2 & & & & \\
\hline No & 11 & 7.7 & & & & \\
\hline
\end{tabular}




\section{Brief Symptom Inventory (BSI-53)}

The Portuguese version of the BSI-53 (Canavarro, 1999) was used. The BSI-53 is a self-report inventory focused on the assessment of psychopathological symptoms. It has 53 items rated on a 5-point Likert scale, ranging from 0 (never) to 4 (many times), and measures different psychopathological symptoms, such as interpersonal sensitivity, depression, or anxiety. It also has a general factor that was used in the present study. Cronbach's alfa for the total index was considered very high $(\alpha=0.95)$.

\section{UCLA Loneliness Scale (ULS-6)}

The Portuguese version from Neto (2014) was used to measure loneliness. This version of the UCLA is composed of 6 items, ranging on a Likert scale from 1 to 5 , and has a unidimensional structure. Cronbach's alpha coefficient in this study was high (0.92).

\section{Data analyses}

To characterize the sample, descriptive statistics were applied. We assumed normal distribution, which was estimated through skewness and kurtosis analyses - see the results section below. To perform the mediation analysis, we used the macro process for SPSS (Hayes, 2013). Power analysis was calculated with MedPower software (Kenny, 2017). For a power analysis of 0.80 for indirect effects, a sample size of 113 individuals was required. The sample size of the present study is $\mathrm{N}=142$, which is adequate to perform the intended mediations. Confidence intervals of $95 \%$ and a 10,000 number of bootstrap computations were used in the two mediations. All statistical procedures were conducted in IBM SPSS version 24.

\section{Results}

Table 2 shows the means, standard deviations, amplitude, minimum and maximum statistics of the variables under study. According to Brow (2006) skewness values between -3 and +3 and kurtosis values between -10 to +10 are adequate when utilizing Structural Equations Models (SEM). Therefore, in the present study, skewness and kurtosis seem acceptable.

Medium to strong correlations were found between psychological needs, symptomatology, loneliness, wellbeing, and distress $(\mathrm{P}<0.001)$. The regulation of psychological needs was negatively correlated with symptomatology $(r=0.64, \mathrm{P}<0.001)$, loneliness $(r=-$ $0.50, \mathrm{P}<0.001)$ and psychological distress $(r=-0.63$, $\mathrm{P}<0.001$ ), and was positively correlated with psychological well-being $(r=-0.66, \mathrm{P}<0.001)$ (Table 3$)$.

Two composite mediation models were tested to explore if psychological distress and well-being (as measured by the MHI) were significant mediators of the relationships between loneliness (as measured by the ULS-6) and the regulation of psychological needs (as measured by the NSRS-43) and between loneliness and symptomatology (as measured by the BSI). Both models were significant.

In the first model, psychological well-being $(\mid 0.056$, $0.184 \mid, b=0.109, \mathrm{P}<0.005)$ and psychological distress $(|0.139,0.341|, b=0.241, \mathrm{P}<0.05)$ were significant mediators of the relationships between loneliness and symptomatology (Figure 1). In the second model, psychological well-being $(|-0.630,-0.117|, b=-0.204$, $\mathrm{P}<0.05)$ and psychological distress $(|-0.325,-0.095|, b=$ $-0.204, \mathrm{P}<0.05)$ were significant mediators of the rela-

Table 2. Means, standard deviations, amplitude, minimum and maximum statistics of the variables under study ( $\mathrm{N}=142)$.

\begin{tabular}{lcccccccc}
\hline & Mean & DP & Amp & Min & Max & Skewness & Kurtosis \\
\hline Psychological needs & 6.03 & 0.88 & 4.78 & 0.88 & 7.66 & -0.71 & 0.45 \\
\hline Symptomatology & 0.87 & 0.66 & 3.30 & 0.00 & 3.30 & 1.11 & 1.08 \\
\hline Loneliness & 1.34 & 0.54 & 2.50 & 0.33 & 2.83 & 0.32 & -0.50 \\
\hline Well-being & 12.96 & 0.07 & 14.00 & 4.00 & 18.00 & -1.01 & 0.55 \\
\hline Distress & 7.96 & 0.01 & 14.00 & 3.00 & 17.00 & 1.02 & 0.61 \\
\hline
\end{tabular}

Table 3. Pearson correlations between psychological needs, symptomatology, loneliness, well-being, and distress (N=142).

\begin{tabular}{lccccc}
\hline & $\mathbf{1}$ & $\mathbf{2}$ & $\mathbf{3}$ & $\mathbf{4}$ & $\mathbf{5}$ \\
\hline Psychological needs & 1 & $-0.66^{* *}$ & $-0.50^{* *}$ & $0.66^{* *}$ & $-0.66^{* *}$ \\
\hline Symptomatology & & 1 & $0.58^{* *}$ & $-0.76^{* *}$ & $0.77^{* *}$ \\
\hline Loneliness & & 1 & $-0.45^{* *}$ & 0.43 \\
\hline Well-being & & & 1 & $-0.95^{* *}$ \\
\hline Distress & & & 1 \\
\hline
\end{tabular}

$* * \mathrm{P}<0.001 .1=$ psychological needs; $2=$ symptomatology; $3=$ loneliness; $4=$ well-being; $5=$ distress. 
tionships between loneliness and the regulation of psychological needs (Figure 2).

\section{Discussion}

The results corroborated our hypotheses. All variables under study were correlated, which supports our theoret- ical predictions (confirmation of hypothesis 1 ). These results imply that the associations between these variables are significant, wherein individuals who experience feelings of loneliness have lower levels of psychological wellbeing and higher levels of psychological distress, symptomatology, and difficulties in the regulation of psychological needs.

Loneliness predicts symptomatology, and this rela-

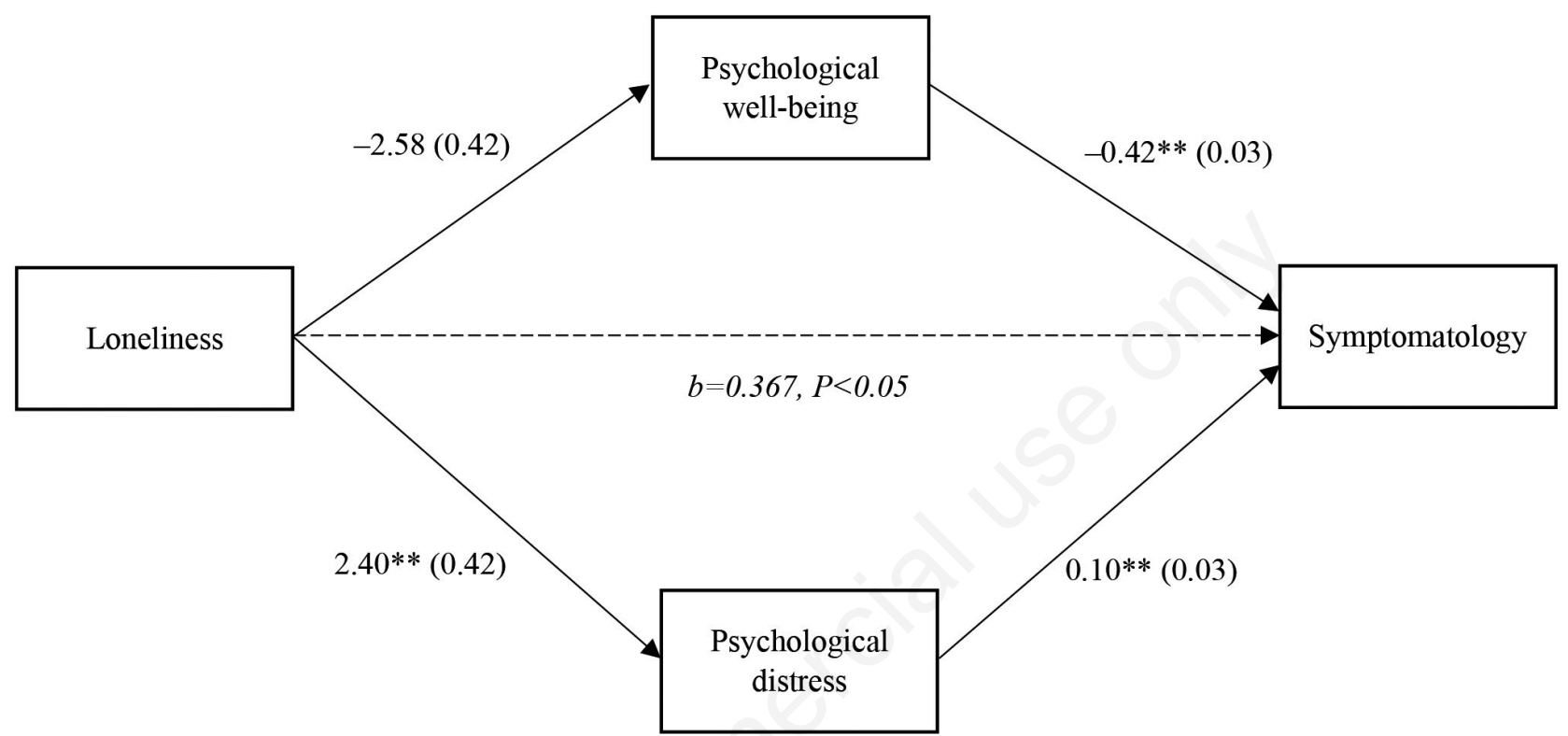

Figure 1. Mediation model between loneliness and symptomatology with distress and well-being as mediators. Only significant standardized values are showed.

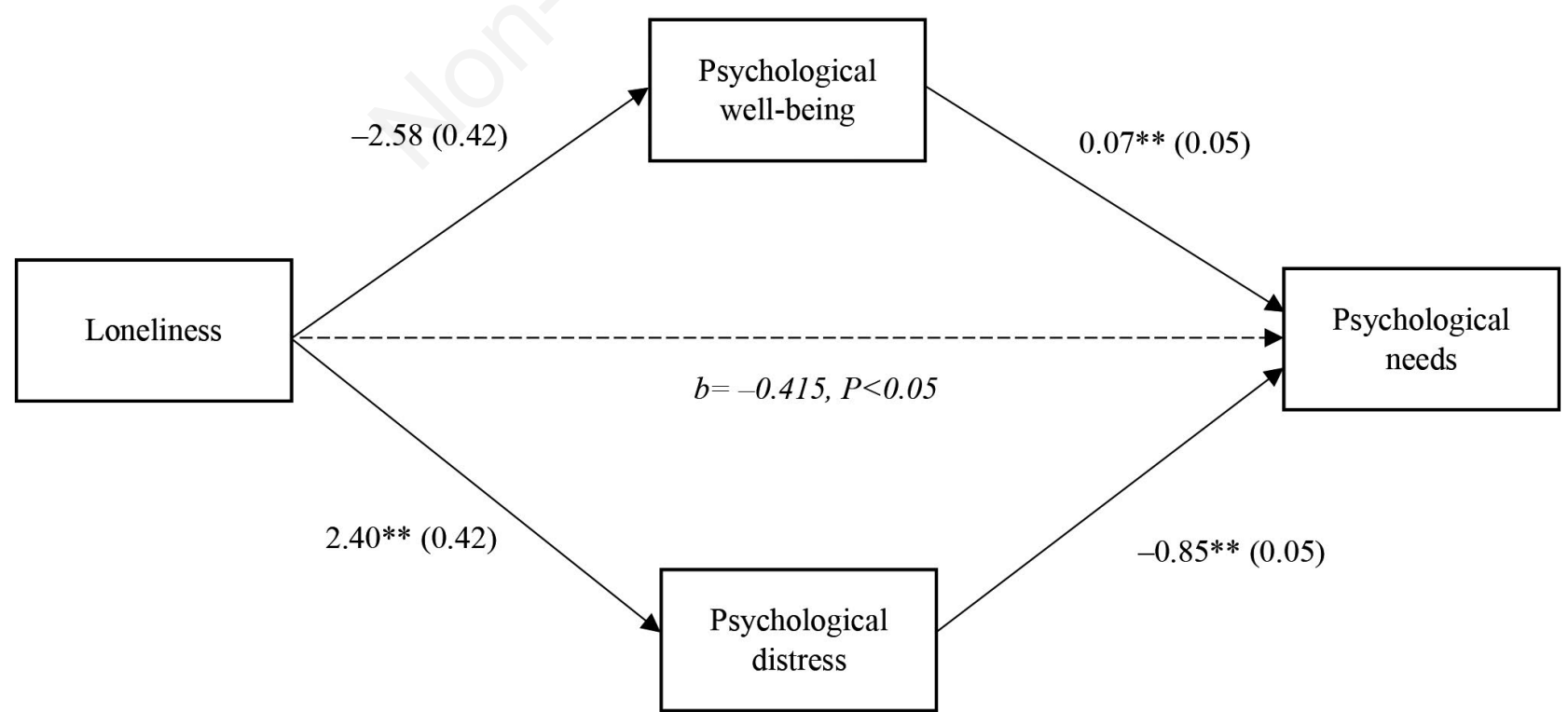

Figure 2. Mediation model between loneliness and psychological needs with distress and well-being as mediators. Only significant standardized values are showed. 
tionship is mediated by psychological distress and psychological well-being (confirmation of hypothesis 2). These results are in line with previous findings, where loneliness was associated with psychological distress and symptomatology (Gerino et al., 2017; Neto, 2014). Loneliness seems to be a key factor in the emergence of psychopathological symptoms, which was anticipated by several authors as a consequence of COVID-19 lockdowns and/or quarantine (Dickerson, 2020; Hiremath et al., 2020; Roy et al., 2020; Wang et al., 2017; Zandifar \& Badrfam, 2020). In this sense, these results may highlight the need for psychological interventions regarding feelings of loneliness and isolation and their relationships with psychological distress and well-being. A wide range of guidelines and psychological interventions are already described (Banerjee, 2020; Brooks et al., 2020) and our evidence may contribute to emphasize clinically relevant domains as targets of psychotherapeutic procedures.

Loneliness also predicts difficulties in the regulation of psychological needs, and this relationship is mediated by psychological distress and psychological well-being (confirmation of hypothesis 2). These results were expected due to the relationships previously described (Barreira, 2016; Castelo-Branco, 2016; Faustino \& Vasco, 2020a, b, c; Faustino, Vasco, Silva, \& Marques, 2020; Fonseca, 2012; Martins, 2016; Sol \& Vasco, 2017). One likely explanation may be given for this result. Individuals may start to experience feelings of loneliness, sadness, and emptiness because of the self-imposed quarantine, which implies social distancing, and these feelings may facilitate the emergence of psychological distress and the lowering of psychological well-being, which in turn decreases the ability to regulate psychological needs. Thus, the regulation of psychological needs is signaled by the emotional system, which seems to be the one who is most vulnerable in the COVID-19 pandemic. Moreover, this assumption seems to be supported by the mediation analysis reported here.

One major aspect that would have some impact on the experience of loneliness may be the presence of early maladaptive schemas. Several studies showed that dysfunctional schemata mediate several psychological constructs and symptomatology, such as emotional processing difficulties (Faustino \& Vasco, 2020c), co-rumination (Balsamo, Carlucci, Sergi, Klein Murdock, \& Saggino, 2015), attachment (Roelofs, Lee, Ruijten, \& Lobbestael 2011), and perceptions of early parenting (Schatzman, 2009). In this sense, it would be interesting to explore how these schemas may exacerbate the experience of COVID-19 related loneliness. If our predictions are supported, early maladaptive schemas may be considered as targets for psychological intervention regarding the experience of COVID-19 related loneliness.

According to this preliminary data, it is possible to emphasize that integrative case conceptualization regarding psychological problems related to COVID-19 may take into consideration different aspects of human experiences, such as psychological needs and relational domains. To work on psychological needs, several strategies may be used, such as consciousness awareness, reattribution, reenactment tasks, or even experiential focusing (Faustino \& Vasco, 2020c). To work on relational domains, such as loneliness, several recommendations may be given to specifically address feelings of loneliness. Hawkley and Cacioppo (2010) documented four major strategies to deal with the experience of loneliness: i) enhance social skills, ii) provide social support, iii) enhance opportunities for social interaction, and iv) address maladaptive social cognition. These general strategies may be applied to reduce the experience of loneliness, in combination with other therapeutic tasks to soothe general distress and symptomatology (e.g., diaphragmatic breathing, muscle relaxation, the imagery of a safe place, or grounding techniques). In this sense, integrative modalities of intervention may be used to soothe the experience of loneliness, distress, and increase mental health.

\section{Recommendations and proposed guidelines}

Despite the existence of general therapeutic tasks to cope with psychological distress/wellbeing and loneliness, we believe that some specific guidelines may be proposed to help mental health professionals work with their clients. These suggestions may be viewed as preventive/proactive and/or supportive actions that could be used to deal with distress and to temper perceived loneliness and/or other symptomatology.

Therefore, clinical psychologists, psychotherapists, and psychiatrists may also help clients to: i) keep connecting with others; ii) keep things in perspective; iii) acknowledge their feelings; iv) focus on a social mentality (you are not alone); v) get creative and learn something new; vi) maintain day-to-day normal activities and routines where possible; vii) seek accurate information (understanding the risk); viii) avoid too much exposure to the news (set limits to the media); ix) seek help when or if needed; and x) follow their local health policies to be safe (protect themselves and others). These guidelines are detailed below.

Keeping connected to, and sharing distressful emotions with family, friends, neighbors, co-workers, may help soothing feelings of loneliness and distress. The connection can bring a sense of comfort, security, and stability. By keeping things in perspective, clients may come to realize that crises are transitory events that have a beginning and an end; this moreover, perspective may boost hope, confidence, and optimism (adaptive attitude and resilience).

Clinical psychologists and psychotherapistsClinical psychologists mat help clients to focus on their feelings which may help them to be conscious of needs and emotions which need to be expressed (talking, writing, creat- 
ing, meditating...). Focusing on social mentalities may stimulate a sense of wholeness and of sense of shared values and needs, which in turn may sooth distressful thoughts and feelings of loneliness. Also, instructing individuals in getting creative and exploring past hobbies and new activities (puzzles, writing...), could help to focus their attention on pleasurable moments, which in turn may boost psychological well-being. It may be useful to instruct individuals to maintain day-to-day normal activities and routines where possible, such as eating healthy with well-balanced meals, exercising regularly, and getting plenty of sleep, promoting routine adherence and stability.

Moreover, it is important to stimulate individuals to seek accurate information (understanding the risk), by finding credible sources that they can trust which may help to avoid fear and panic. Thus, informing individuals to avoid too much exposure to the news (setting limits to the media), by taking breaks from watching, reading, or listening to news stories, to prevent them from becoming upset due to repeatedly hearing about the crisis and seeing related images. Also, mental health professionals may instruct individuals to seek help if they need it, since if distress impacts their daily life individuals should benefit from talking to mental health care professionals. Finally, individuals should be instructed to follow their local health policies to be safe and to respect local government rules and health guidelines (protect themselves and others).

Furthermore, we suggest that mental health services (e.g., public hospitals, health centers, private mental health services), should keep online information updated, with updated public phone numbers, email addresses, physical addresses, and clinical staff, to provide accurate information to potential clients. Thus, health care services may also reinforce staff not only to help potential clients but also to provide support to other clinicians how may be at risk.

\section{Limitations and future directions}

Despite the study's strengths, it is possible to describe some limitations. This study was conducted on-line using a cross-sectional design, which may limit some causal explanations about the variables under study. Thus, it would be interesting to replicate this study on a clinical sample. Another limitation may be the use of self-report measures which are limited to individuals' self-awareness. The sample was unbalanced regarding gender, as most of the sample was female. Differences in the experience of loneliness between men and women are documented (Borys \& Perlman, 1985). However, across the lifespan, levels of loneliness may be similar (Maes, Qualter, Vanhalst, Noortgate, \& Luc Goossens, 2019). In this sense, future studies should focus on this issue, in order to explore gender differences when it comes to the experience of COVID-19 related loneliness. Moreover, the sample size is small, which limits generalization and statistical power.
This study was conducted in a sample that mainly consisted of young adults, with a high education level and mostly single. This implies that our conclusions are based on a strict demographic level of the population, which is why generalizations should be made with caution. On the one hand, individuals who are single and highly educated may have lower levels of perceived loneliness because they may satisfy proximity needs with technological devices and social media. On the other hand, these individuals may also crave social proximity due to their life stage, which may be influenced by interpersonal motivations of social inclusion and relatedness. Thus, more research is required to explore these issues.

Different types of loneliness may represent different meanings (Weiss, 1973). Our study focused on perceived loneliness associated with social distancing regarding COVID-19 lockdown in a generic manner. Therefore, a detailed analysis of demographic data (e.g., living alone, having a family) would be useful to differentiate different types of the severity of loneliness.

Detailed relationships between specific needs and symptoms were not explored in the present study. In the future, we will address this issue with a more in-depth analysis of the relationships between different psychological needs and different symptomatology. Future research should also focus on conducting longitudinal studies to better understand variations in loneliness, symptoms, and psychological needs during the period associated with the COVID-19 pandemic. Finally, this preliminary study belongs to a wider line of research that intends to explore the impacts of the COVID-19 pandemic on mental health.

\section{Conclusions}

Loneliness may have pervasive impacts on mental health indexes (such as psychological distress and wellbeing), psychopathological symptoms, and the regulation of psychological needs. These preliminary results add to the yet limited literature on the impacts of the COVID-19 pandemic on mental health and may inform clinical psychologists and psychotherapists regarding case conceptualization and clinical decision making.

\section{References}

Ascher, S. R. \& Paquette, J. A. (2003). Loneliness and peer relations in childhood. Current Direction of Psychological Science, 12, 75-78. doi: 10.1111/1467-8721.01233

Balsamo, M., Carlucci, L., Sergi, M. R., Klein Murdock, K., \& Saggino, A. (2015). The mediating role of early maladaptive schemas in the relation between co-rumination and depression in young adults. PLoS One, 10(10), e0140177. https://doi.org/10.1371/journal.pone.0140177

Banerjee, D. (2020). The COVID-19 outbreak: the crucial role the psychiatrists can play. Asian Journal of Psychiatry. 50, 102014. https://doi.org/10.1016/j.ajp.2020.102014. 
Barreira, J. (2016). Relações entre dificuldades de processamento emocional, regulação emocional, necessidades psicológicas, sintomatologia e bem-estar/distress. [Relationship between emotional processing difficulties, emotional regulation, psychological needs, symptomatology, and wellbeing/distress.] Master thesis in Faculty of Psychology of University of Lisbon.

Borys, S., \& Perlman, D. (1985). Gender differences in loneliness. Personality and Social Psychology Bulletin, 11(1), 6374. https://doi.org/10.1177/0146167285111006

Brooks, S.K., Webster, R.K., Smith, L.E., Woodland, L., Wessely, S., Greenberg, N., Rubin, G.J. (2020). The psychological impact of quarantine and how to reduce it: rapid review of the evidence. The Lancet. Advance online publication.

Cacioppo, J. T., \& Cacioppo, S. (2018). The growing problem of loneliness. Lancet (London, England), 391(10119), 426. https://doi.org/10.1016/S0140-6736(18)30142-9

Canavarro, M. C. (1999). Inventário de sintomas psicopatológicos -BSI. In M. R. Simões, M. Gonçalves, L. S. Almeida (Eds.), Testes e Provas Psicológicas em Portugal (Vol. II, pp. 95-109). Braga: APPORT/SHO.

Caspi, A., Harrington, H., Moffitt, T. E., Milne, B. J., \& Poulton, R. (2006). Socially isolated children 20 years later: risk of cardiovascular disease. Archives of Pediatrics \& Adolescent Medicine, 160(8), 805-811. https://doi.org/10.1001/archpedi.160.8.805

Castelo-Branco, M. (2016). Relações entre regulação emocional, regulação da satisfação das necessidades psicológicas, bemestar/distress psicológicos e sintomatologia. [Relationships between emotional regulation, regulation of the satisfaction of psychological needs, psychological well-being/distress and symptomatology]. Master thesis in the Faculty of Psychology of University of Lisbon.

Chan, S. S., Leung, D., Chui, H., Tiwari, A. F., Wong, E. M., Wong, D. C., Barnsteiner, J. H., \& Lau, Y. L. (2007). Parental response to child's isolation during the SARS outbreak. Ambulatory Pediatrics: the Official Journal of the Ambulatory Pediatric Association, 7(5), 401-404. https://doi.org/10.1016/j.ambp.2007.06.002

Conde, E., Vasco, A. B., Ferreira, A., Romão, A. R., Silva, G., Sol, A., \& Vargues-Conceição, C. (2012). Regulação da satisfação de necessidades psicológicas: Influência no bemestar e distress psicológicos e na sintomatologia de acordo com o modelo de complementaridade paradigmática (Unpublished manuscript). Lisbon: Faculdade de Psicologia da Universidade de Lisboa.

Conversano, C., Marchi, L., \& Miniati, M. (2020). Psychological distress among healthcare professionals involved in the COVID-19 emergency: Vulnerability and resilience factors. Clinical Neuropsychiatry: Journal of Treatment Evaluation, 17, 94-96.

Cornwell, E. Y., \& Waite, L. J. (2009). Social disconnectedness, perceived isolation, and health among older adults. Journal of Health and Social Behavior, 50(1), 31-48. https://doi.org/10.1177/002214650905000103

Dickerson, D., (2020). Seven tips to manage your mental health and well-being during the COVID-19 outbreak. Nature. Advance online publication. https://doi.org/10.1038/d41586020-00933-5.

Faustino, B., \& Vasco, A.B. (2020a). Schematic functioning, interpersonal dysfunctional cycles and cognitive fusion in the complementary paradigmatic perspective: Analysis of a clinical sample. Journal of Contemporary Psychotherapy, 1(50),
47-55. https://doi.org/10.1007/s10879-019-09422-x

Faustino, B., \& Vasco, A.B. (2020b). Early maladaptive schemas and cognitive fusion on the regulation of psychological needs. Journal of Contemporary Psychotherapy, 1(50), 105112. https://doi.org/10.1007/s10879-019-09446-3

Faustino, B., \& Vasco, A.B. (2020c). Relationships between emotional processing difficulties and early maladaptive schemas on the regulation of psychological needs. Clinical Psychology and Psychotherapy. Advance online publication. https://doi.org/10.1002/cpp.2464

Faustino, B., Vasco, A.B., Silva A. N., \& Marques, T.(2020). Relationships between emotional schemas, mindfulness, selfcompassion and unconditional self-acceptance on the regulation of psychological needs. Research in Psychotherapy: Psychopathology, Process and Outcome, 23(2), 145156. doi:10.4081/ripppo.2020.442

Fonseca, J. M. (2012). Relação entre a regulação da satisfação das necessidades psicológicas, funcionamento esquemático e alexithymia. [Relationship between the regulation of satisfaction of psychological needs, schematic functioning and alexithymia]. Lisbon: Faculdade de Psicologia.

Gerino, E., Rollè, L., Sechi, C., \& Brustia, P. (2017). Loneliness, resilience, mental health, and quality of life in old age: a structural equation model. Frontiers in Psychology, 8, 2003. https://doi.org/10.3389/fpsyg.2017.02003

Hayes, A. F. (2013). Introduction to mediation, moderation, and conditional process analysis: A regression-based approach. New York: Guilford Press.

Hawkley, L. C., \& Cacioppo, J. T. (2010). Loneliness matters a theoretical and empirical review of consequences and mechanisms. Annals of Behavioral Medicine: a publication of the Society of Behavioral Medicine, 40(2), 218-227. https://doi.org/10.1007/s12160-010-9210-8

Hawkley, L. C., Browne, M. W., \& Cacioppo, J. T. (2005). How can I connect with thee? Let me count the ways. Psychological Science, 16(10), 798-804. https://doi.org/10.1111/j. 1467-9280.2005.01617.x

Hawryluck, L., Gold, W. L., Robinson, S., Pogorski, S., Galea, S., \& Styra, R. (2004). SARS control and psychological effects of quarantine, Toronto, Canada. Emerging Infectious Diseases, 10(7), 1206-1212. https://doi.org/10.3201/ eid1007.030703

Hiremath, P., Kowshika, S., Manjunath, M., \& Shettara, M. (2020). COVID 19: Impact of lock-down on mental health and tips to overcome, Asian Journal of Psychiatry, 51. Advance online publication. doi: https://doi.org/10.1016/j.ajp. 2020.102088

Holt-Lunstad, J., Smith, T. B., Baker, M., Harris, T., \& Stephenson, D. (2015). Loneliness and social isolation as risk factors for mortality: a meta-analytic review. Perspectives on Psychological Science, 10(2), 227-237.

Kamara, S., Walder, A., Duncan, J., Kabbedijk, A., Hughes, P., \& Muana, A. (2017). Mental health care during the Ebola virus disease outbreak in Sierra Leone. Bulletin of the World Health Organization, 95(12), 842-847. https://doi.org/ 10.2471/BLT.16.190470

Kenny, D. A. (2017). MedPower: An interactive tool for the estimation of power in tests of mediation [Computer software]. Available from https://davidakenny.shinyapps.io/MedPower/.

Liu, X., Kakade, M., Fuller, C. J., Fan, B., Fang, Y., Kong, J., Guan, Z., \& Wu, P. (2012). Depression after exposure to stressful events: lessons learned from the severe acute res- 
piratory syndrome epidemic. Comprehensive Psychiatry, 53(1), 15-23. https://doi.org/10.1016/j.comppsych.2011. 02.003

Liu, Y., Ning, Z., Chen, Y., Guo, M., Liu,Y., Gali, N. K., Sun, L., Duan, Y., Cai, J., Westerdahl, D., Liu, X., Xu, K., Ho, K.F., Kan, H., Fu, Q., \& Lan, K. (2020). Aerodynamic analysis of SARS-CoV-2 in two Wuhan hospitals. Nature 582, 557560. doi: https://doi.org/10.1038/s41586-020-2271-3

Maes, M., Qualter, P., Vanhalst, J., Van den Noortgate, W., \& Goossens, L. (2019). Gender differences in loneliness across the lifespan: a meta-analysis. European Journal of Personality, 33(6), 642-654. https://doi.org/10.1002/per.2220

Masi, C. M., Chen, H. Y., Hawkley, L. C., \& Cacioppo, J. T. (2011). A meta-analysis of interventions to reduce loneliness. Personality and Social Psychology Review: an Official Journal of the Society for Personality and Social Psychology, Inc, 15(3), 219-266. https://doi.org/10.1177/ 1088868310377394

Martins, R. (2016). Relações entre esquemas interpessoais, mecanismos de defesa, necessidades psicológicas, sintomatologia, bem-estar e distress psicológico. [Relations between interpersonal schemes, mechanisms of defense, psychological needs, symptomatology, well-being and psychological distress]. Master thesis in Faculty of Psychology of University of Lisbon.

Marazziti, D., Pozza, A., Di Giuseppe, M., \& Conversano, C. (2020). The psychosocial impact of COVID-19 pandemic in Italy: a lesson for mental health prevention in the first severely hit European country. Psychological Trauma: Theory, Research, Practice, and Policy. Advance online publication. http://dx.doi.org/10.1037/tra0000687

Moukaddam. N. (2019). Fears, outbreaks, and pandemics: lessons learned. Psychiatric Times 26, (11). https://www.psychiatrictimes.com/view/fears-outbreaks-and-pandemics-less ons-learned

Neto, F. (2014). Psychometric analysis of the short-form UCLA Loneliness Scale (ULS-6) in older adults. European Journal of Ageing, 11, 313-319. https://doi.org/10.1007/s10433-0140312-1

Prout, T. A., Zilcha-Mano, S., Aafjes-van Doorn, K., Békés, V., Christman-Cohen, I., Whistler, K., Kui, T., \& Di Giuseppe, M. (2020). Identifying predictors of psychological distress during COVID-19: a machine learning approach. Frontiers in Psychology, 11, 586202. https://doi.org/10.3389/fpsyg. 2020.586202

Qiu, J., Shen, B., Zhao, M., Wang, Z., Xie, B., \& Xu, Y. (2020). A nationwide survey of psychological distress among Chinese people in the COVID-19 epidemic: implications and policy recommendations. General Psychiatry, 33(2), e100213. https://doi.org/10.1136/gpsych-2020-100213

Ribeiro, J. L. (2001). Mental health inventory: Um Estudo de adaptação à população Portuguesa. Psicologia, Saúde e Doença, 2(1), 77-99.

Roelofs, J., Lee, C., Ruijten, T., \& Lobbestael, J. (2011). The mediating role of early maladaptive schemas in the relation between quality of attachment relationships and symptoms of depression in adolescents. Behavioural and Cognitive Psychotherapy, 39(4), 471-479. https://doi.org/10.1017/ S1352465811000117

Roy, D., Tripathy, S., Kar, S. H., Sharma, N., Verma, S. N. \& Kaushal. V. (2020). Study of knowledge, attitude, anxiety \& perceived mental healthcare need in Indian population during COVID-19 pandemic. Asian Journal of Psychiatry, 51. https://doi.org/10.1016/j.ajp.2020.102083.

Russell, D. W. (1996). UCLA Loneliness Scale (Version 3): Reliability, validity, and factor structure. Journal of Personality Assessment, 66(1), 20-40. https://doi.org/10.1207/ s15327752jpa6601_2

Russell, D., Cutrona, C. E., Rose, J., \& Yurko, K. (1984). Social and emotional loneliness: An examination of Weiss's typology of loneliness. Journal of Personality and Social Psychology, 46(6), 1313-1321. https://doi.org/10.1037/00223514.46.6.1313

Salari, N., Hosseinian-Far, A., Jalali, R., Vaisi-Raygani, A., Rasoulpoor, S., Mohammadi, M., Rasoulpoor, S., \& KhalediPaveh, B. (2020). Prevalence of stress, anxiety, depression among the general population during the COVID-19 pandemic: a systematic review and meta-analysis. Globalization and Health, 16(1), 57. https://doi.org/10.1186/s12992-02000589-w

Schatzman, M. (2009). Early maladaptive schemas mediating the relationship between perceptions of early parenting and depression and anxiety. Theses and Dissertations. 668. https://rdw.rowan.edu/etd/668

Shankar, A., McMunn, A., Banks, J., \& Steptoe, A. (2011). Loneliness, social isolation, and behavioral and biological health indicators in older adults. Health Psychology, 30(4), 377.

Sol, A., \& Vasco, A. B. (2017). Relationships between the regulation of psychological needs satisfaction and symptomatology. Psicologia, 31, 1. http://dx.doi.org/10.17575/ rpsicol.v31i1.1135

Sousa, R. D., Rodrigues, A. M., Gregório, M. J., Branco, J. C., Gouveia, M. J., Canhão, H., \& Dias, S. S. (2017). Anxiety and depression in the Portuguese older adults: Prevalence and associated factors. Frontiers in Medicine, 4, 196. https://doi.org/10.3389/fmed.2017.00196

Vasco, A. B., Conceição, N., Silva, A. N., Ferreira, J. F., \& VazVelho, C. (2018). O (meta)modelo de complementaridade paradigmática (MCP). In I. Leal (Ed.), Psicoterapias. Lisbon: Pactor. [Paradigmatic Complementarity Metamodel].

Wang, J., Lloyd-Evans, B., Giacco, D., Forsyth, R., Nebo, C., Mann, F., \& Johnson, S. (2017). Social isolation in mental health: a conceptual and methodological review. Soc Psychiatry Epidemiology, 52, 1451-1461. https://doi.org/ 10.1007/s00127-017-1446-1

Weiss, R. S. (1973). Loneliness: The experience of emotional and social isolation. Cambridge, MA: MIT Press.

World Health Organization (WHO), 2020a. Coronavirus Disease 2019 (COVID-19) Situation Report - 69. Geneva: World Health Organization.

World Health Organization (WHO), 2020b. Mental health and psychosocial considerations during the COVID-19 outbreak, 18 March 2020. Geneva: World Health Organization.

Zandifar, A., \& Badrfam, R. (2020). Iranian mental health during the COVID-19 epidemic. Asian Journal of Psychiatry, 51, 101990. https://doi.org/10.1016/j.ajp.2020.101990.

Ziegler, T., Mamahit, A., \& Cox, N. J. (2018). 65 years of influenza surveillance by a World Health Organization-coordinated global network. Influenza and Other Respiratory Viruses, 12(5), 558-565. https://doi.org/10.1111/irv.12570 